\title{
Therapeutic Outcome of Primary Snoring and Mild Obstructive Sleep Apnea and Clinical Suggestion for Treatment Approaches
}

\author{
Seulki Song, Yoonjae Song, Han Gyeol Park, Jinil Kim, Sung dong Cho, \\ Jeong-Yeon Ji, Young Seok Kim, and Hyun Jik Kim \\ Department of Otorhinolaryngology-Head and Neck Surgery, Seoul National University College of Medicine, Seoul, Korea
}

\author{
단순 코골이와 경증 폐쇄성수면무호흡의 치료 결과와 치료 방법에 대한 임상적 평가 \\ 송슬기 · 송윤재 · 박한결 · 김진일 · 조성동 · 지정연 · 김영석 · 김현직 \\ 서울대학교 의과대학 이비인후과학교실
}

Received May 23, 2018

Revised July 12,2018

Accepted July 17, 2018

Address for correspondence

Hyun Jik Kim, MD, PhD

Department of Otorhinolaryngology-

Head and Neck Surgery,

Seoul National University

College of Medicine,

101 Daehak-ro, Jongno-gu,

Seoul 03080, Korea

Tel $+82-2-2072-2203$

Fax $+82-2-2735-2387$

E-mail hyunjerry@snu.ac.kr

Background and Objectives The clinical significance and need for the treatment of primary snoring and mild obstructive sleep apnea have been recently questioned. In this study, we analyzed therapeutic outcome and the methods of treatment of such diseases.

Subjects and Method A retrospective review was conducted using the medical records of patients diagnosed with primary snoring or mild obstructive sleep apnea at a single institution from 2013 to 2015 through polysomnography or WATCHPAT.

Results Of the 18 patients $(37 \%)$ with primary snoring, 13 patients $(72.2 \%)$ underwent surgery, four patients $(22.2 \%)$ were treated with surgery and mandibular advancement device, and one patient $(5.6 \%)$ underwent automatic positive airway pressure therapy. Of the 78 patients $(61 \%)$ with mild obstructive sleep apnea, 35 patients $(44.8 \%)$ had surgery, 24 patients $(30.8 \%)$ were treated with mandibular advancement device, 13 patients $(16.7 \%)$ were treated with surgery and mandibular advancement device and 6 patients $(7.7 \%)$ received automatic positive airway pressure therapy. For primary snoring, while Epworth Sleepiness Scale and Pittsburg Sleep Quality Index did not improve, the snoring visual analog scale decreased significantly. In patients with mild obstructive sleep apnea, Apnea-Hypopnea Index, snoring decibel, Epworth Sleepiness Scale, and Pittsburg Sleep Quality Index were significantly decreased after treatment and the lowest oxygen saturation was significantly increased after treatment. Conclusion For primary snoring, the direction of treatment should be determined in accordance with the presence of associated diseases related to sleep disturbance breathing. For mild obstructive sleep apnea, active treatment may be helpful.

Korean J Otorhinolaryngol-Head Neck Surg 2019;62(2):102-7

Key Words Mild obstructive sleep apnea · Outcome · Primary snoring.

\section{서 론}

폐쇄성수면무호흡은 매우 높은 빈도의 질환으로, 최근 성

This is an Open Access article distributed under the terms of the Creative Commons Attribution Non-Commercial License (https://creativecommons.org/licenses/by-nc/4.0) which permits unrestricted non-commercial use, distribution, and reproduction in any medium, provided the original work is properly cited.
인 남자의 $50 \%$ 이상에서 다양한 정도의 수면호흡장애를 가 지는 것으로 보고하고 있다. ${ }^{1)}$ 특히 고령의 환자에서 더 흔하 며, 최근 연구에 따르면 중년에서 고령의 남자의 $79 \%$ 가 전통 적인 진단 기준 ${ }^{2}$ 에서 폐쇄성수면무호흡으로 진단된다고 한 다.) 또 다른 최근 연구에서도 일반 인구에서 폐쇄성수면무호 흡의 높은 빈도에 대해 보고하였으나, 대부분의 환자는 그 
증상이 적고, 무호흡-저호흡지수(Apnea-Hypopnea Index, $\mathrm{AHI}$ 와 일치하지 않는 경우가 많음을 함께 지적하였다. ${ }^{4}$

수면호흡장애의 대표적인 증상인 코골이는 수면 파트너에 게도 소음으로 인한 수면 방해를 유발하고 사회적으로 고립 을 야기할 뿐만 아니라 폐쇄성수면무호흡증이 동반되는 경우 환자 본인에게 더 심각한 합병증을 유발할 수 있다. 폐쇄성 수면무호흡 환자는 수면 중 흡기 시에 발생하는 인두 내 음압 (negative pressure)이 정상 기도를 유지하고자 하는 이완근 의 능력을 초과하면서, 반복적인 상기도 폐쇄가 일어나며 ${ }^{5)}$ 수면 중에 좁아진 상기도로 호흡기류가 지나면서 인두 주위 구조물에 진동을 일으켜 코골이가 발생한다. ${ }^{6}$ 기존의 연구 에 따르면 코골이의 유병률은 진단 기준에 따라 차이가 크며, 전체 성인 남성의 $10.8 \sim 64 \%$, 여성의 3.5 52\%에서 습관성으 로 코골이가 나타나며 특히 나이가 60세 이상의 경우에는 그 빈도가 더 증가하는 것으로 알려져 있다. ${ }^{7)}$ 하지만 단순 코골 이가 반드시 치료가 시행되어야 하는지에 대해서는 아직 연구 보고마다 그 결론이 다르고 아직 치료 원칙 및 치료 방법 선 택 등에 대한 지침이 정해져 있지 않다. 다양한 보고들에서 단순 코골이와 경증 폐쇄성수면무호흡은 더욱 그 임상적 중 요성 및 치료 여부에 대한 의문점이 제기되고 있고, 이들의 치 료 결정 및 원칙에 대한 위한 새로운 요구가 늘어나고 있다. 이에 본 연구자들은 단순 코골이와 경증 폐쇄성수면무호흡 으로 진단받은 환자들에게 시행한 치료 방법들에 대한 고찰 및 그 치료 결과에 대한 분석을 통해 적절한 치료 방향을 알 아보고자 본 연구를 진행하였다.

\section{대상 및 방법}

본 연구는 후향적 임상 연구로 2013년 1월부터 2015년 12월 까지 단일 기관에서 코골이와 무호흡을 주소로 이비인후과 외래를 방문한 환자 중 수면다원검사 또는 간이수면다원검 사(WATCH PAT)를 통해 단순 코골이 또는 경증 폐쇄성수 면무호흡으로 진단받은 환자들을 대상으로 하였다. 해당 연구 는 서울대학교병원의 임상연구심의위원회의 승인(IRB No. 1801-084-915)을 받은 후 후향적으로 진행되었다. 이 중 신경 정신과적 질환 및 치매 병력자, 최근 알코올 및 약물 남용자, 인지기능장애(뇌병변 질환이나 뇌수술 병력)가 있는 환자, 그 리고 수면다원검사 상 다른 수면 질환이 동반된 환자는 제외 하였다. 연구대상자들은 숙련된 이비인후과 의사에게 구강 및 비강검진, 수면유도내시경검사(drug induced sleep endoscopy, DISE)를 받았다. 본 기관에서는 수면 유도를 위해 IV bolus 로 미다졸람을 투여하였고 이후 내시경검사를 앙와위, 측와 위 그리고 앙와위 순으로 시행하였다. 수면내시경검사의 결과
는 Kezirian 등이 이 보고한 VOTE classification의 해부학적 구조별 폐쇄의 정도와 양상에 따라 기술하였다. 그리고 치료 전 앱워스수면척도(Epworth Sleepiness Scale, ESS), 피츠버 그 수면 질 척도(Pittsburg Sleep Quality Index, PSQI)를 시 행했다. 각 연구 대상자들은 수술적 또는 비수술적 치료를 받았고 각 환자들이 받은 수술적 치료의 방법 및 수술 술기, 그리고 양압기(ResMed, S9, Bella Vista, Australia) 혹은 구강 내 장치(Somnomed, Somnodent, Crows Nest, Australia) 등 비수술적 치료의 종류 등을 조사하였다. 치료 후 평균 3개 월에 치료 후 수면다원검사 또는 간이수면다원검사 및 ESS, $\mathrm{PSQI}$ 를 시행했다. 치료 전과 치료 후에 같은 종류의 수면다 원검사를 시행하였으며 구강 내 장치의 경우 착용을 한 상태 로 검사를 시행하였다. 후향적 의무기록 및 수면다원검사 분 석을 통해 치료 전후로 수면다원검사에서 $\mathrm{AHI}$, 최저 산소포 화도, 코골이 데시벨, $\mathrm{ESS}$, 그리고 PSQI를 비교하였다. 단순 코골이군에서는 치료 전후의 $\mathrm{AHI}$ 를 비교하는 것이 의미가 없다고 저자들은 판단하여 외래에 방문한 환자들에게 직접 질의응답 형식으로 코골이 Visual Analog Scale(VAS)을 확 인하였고, 이를 의무기록을 통해 수집하였다. 본 기관의 수면 다원검사를 통해서는 Respiratory Disturbance Index(RDI) 를 구할 수 없고 간이수면다원검사를 통해서만 구할 수 있 어, 이에 대한 분석은 제외하였다. 모든 통계는 SPSS 통계 프 로그램(version 20.0 for windows; IBM Corp., Armonk, NY, USA)을 사용하였고 단순 코골이군과 경증 폐쇄성수면무호 흡군 간의 비교를 위해 Mann Whitney U 검정을 시행하였 고, 치료 전후로 변수들의 변화를 확인하기 위해 Wilcoxon 부호순위 검정을 시행하였다. 이때 $p$ 값이 0.05 미만인 경우 통계학적으로 유의미한 것으로 판단하였다.

\section{결 과}

대상 기간 동안 단순 코골이 또는 경증 폐쇄성수면무호흡 으로 진단받아 연구에 포함되고 치료를 권했던 환자는 총 178 명이었으며, 이 중 단순 코골이로 진단받은 환자는 49명 (28\%), 경증 폐쇄성수면무호흡으로 진단받은 환자는 129명 (72\%)이었다(Fig. 1). 연령, 신체비만지수(body mass index, $\mathrm{BMI}), \mathrm{AHI}$, 최저 산소포화도의 경우 통계학적으로 유의한 차이를 보였다(Table 1). 경증 폐쇄성수면무호흡군의 평균 연 령은 42.4세로 단순 코골이군(33.3세)보다 통계학적으로 유 의미하게 높았고, 신체비만지수 역시 경증 폐쇄성수면무호흡 군에서 더 높았다. 수면다원검사 혹은 간이수면다원검사로 측정한 경증 폐쇄성수면무호흡군의 평균 $\mathrm{AHI}$ 는 9.9 였으며 단순 코골이군(평균 $\mathrm{AHI}$ 3.1) 보다 의미 있게 높았으며 최저 
Fig. 1. Total subjects of primary snoring and mild OSA. OSA: obstructive sleep apnea, MAD: mandibular advancement device, PAP: positive airway pressure.

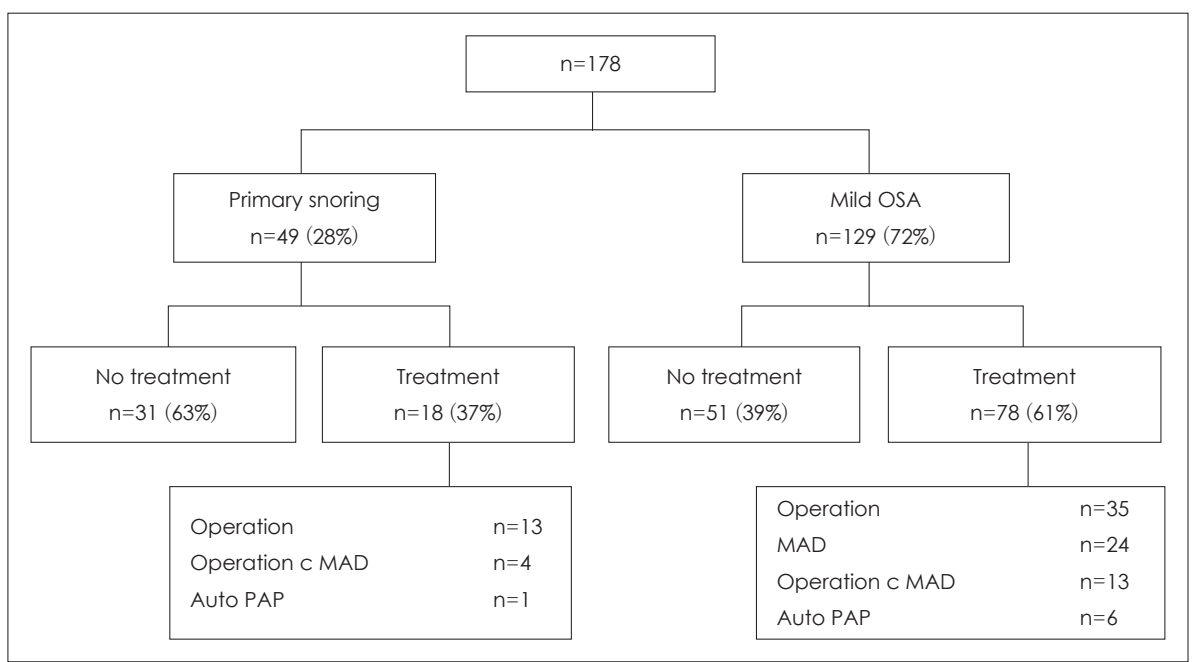

Table 1. Comparison of primary snoring with mild OSA

\begin{tabular}{lccc}
\hline & Primary snoring & Mild OSA & $p$ \\
\hline Age (year) & $33.3 \pm 14.2$ & $42.4 \pm 15.0$ & $0.000^{*}$ \\
BMI & $23.5 \pm 4.5$ & $24.6 \pm 3.1$ & $0.036^{*}$ \\
AHI & $3.1 \pm 1.4$ & $9.9 \pm 2.9$ & $0.000^{*}$ \\
O2 lowest (\%) & $90.1 \pm 4.9$ & $86.6 \pm 4.6$ & $0.000^{*}$ \\
Snoring (dB) & $46.8 \pm 5.7$ & $46.7 \pm 5.5$ & 0.821 \\
ESS & $6.9 \pm 4.6$ & $8.5 \pm 4.2$ & 0.070 \\
PSQI & $6.8 \pm 3.0$ & $7.8 \pm 3.0$ & 0.091 \\
\hline
\end{tabular}

$* p<0.05$ value was accepted as significant level. OSA: obstructive sleep apnea, BMI: body mass index, AHI: Apnea-Hypopnea Index, ESS: Epworth Sleepiness Scale, PSQI: Pittsburg Sleep Quality Index

산소포화도는 경증 폐쇄성수면무호흡군에서 유의미하게 낮 았다. 각 군 간의 코골이 데시벨, $\mathrm{ESS}, \mathrm{PSQI}$ 의 경우 통계학적 으로 유의미한 차이는 없었으나 경증 폐쇄성수면무호흡군에 서 상대적으로 높은 경향성을 보였다.

치료는 수면다원검사 및 수면유도내시경검사 결과를 토대 로 환자와 상의 후에 결정을 하였으며 치료 방법은 수술, 하악 전방위치장치, 수술과 하악전방위치장치를 같이 시행, 자동형 양압기(autoPAP; ResMed)로 크게 4가지 방법으로 시행되었 다. 단순 코골이군 49 명 중 31 명 $(63 \%)$ 은 수면다원검사에서 코골이는 확인되었지만 수면파트너가 증상의 심각도를 호소 하지 않았고 환자도 주관적인 증상(주간기면증, 두통, 만성 피로감, 수면 분절)을 호소하지 않아 특정한 치료를 권하지 않고 경과 관찰만 시행하였으며 이 환자 중 외래 추적 관찰 에서 증상이 더 심해져서 치료를 받게 된 환자는 없었다. 단 순 코골이군에서 18명(37\%)은 치료를 시도하였으며 수술을 받은 환자는 13 명(72.2\%), 수술과 하악전방위치장치를 같이 시행 받은 환자가 4명(22.2\%), 그리고 자동형양압기를 사용 한 환자가 1 명 $(5.6 \%)$ 이었다. 경증 폐쇄성수면무호흡군 129 명
중에서 51명(39\%)의 환자는 단순 코골이군과 마찬가지로 수 면유도내시경검사상 Grade II 이상의 심각한 폐쇄부위가 관 찰되지 않았고 환자가 주관적인 증상을 호소하지 않아 경과 관찰만 시행하였다. 78 명 $(61 \%)$ 의 환자에서 경증 폐쇄성수면 무호흡에 대한 치료를 시도하였으며 수술을 받은 환자가 35 명(44.8\%), 하악전방위치장치 24명(30.8\%), 수술과 하악전방위 치장치를 같이 시행 받은 환자가 13 명(16.7\%), 그리고 자동형 양압기를 사용한 환자가 6명 $(7.7 \%)$ 이었다. 해부학적으로 폐 쇄되는 부위를 수면유도내시경검사로 확인하였고 수술방법 결정에 그 결과를 활용하였다. 단순 코골이군 중 앙와위에서 31 명(63.2\%)은 연구개 부위, 38명(77.6\%)은 설기저부에서 Grade I 이상의 폐쇄 소견을 보였다. 경중 폐쇄성수면무호흡 군 역시 대부분의 폐쇄부위가 연구개(100명, 77.5\%)와 설기 저부(94명, 72.9\%)에서 관찰되었다. 단순 코골이와 경증 폐쇄 성수면무호흡 환자들에서 후두개 폐쇄와 편도선 비대는 상 대적으로 낮은 빈도로 관찰되었다(Table 2).

단순 코골이군에서 수술을 받은 17명의 환자 중 9명(52.9\%) 은 비중격 교정술 및 하비갑개 성형술을 받았고, 3명(17.6\%) 은 비중격 교정술 및 하비갑개 성형술, 그리고 설기저부 축소 술을 받았고, 3명(17.6\%)은 비중격 교정술 및 하비갑개 성형 술 그리고 양측 편도절제술을 시행 받았고, 2명(11.8\%)은 비 중격 교정술 및 하비갑개성형술 또는 구개수성형술을 시행 받았다(Fig. 2A), 경증 폐쇄성수면무호흡군에서 수술을 받 은 48명 중 25명(52.1\%)은 비중격 교정술 및 하비갑개 성형술, 구개수 성형술, 그리고 측인두 성형술을 받았고, 12 명(25\%)은 비중격 교정술 및 하비갑개 성형술, 그리고 구개수 성형술을 받았고, 5명(10.4\%)은 비중격 교정술 및 하비갑개 성형술, 측 인두 성형술, 그리고 설기저부 축소술을 받았고, 3 명(6.3\%)은 측인두 성형술만 받았다(Fig. 2B). 
Table 2. Result of drug induced sleep endoscopy

\begin{tabular}{lccccc}
\hline \multirow{2}{*}{ Obstruction site } & \multicolumn{2}{c}{ Supine position } & & \multicolumn{2}{c}{ Lateral position } \\
\cline { 2 - 3 } \cline { 5 - 6 } & Primary snoring $(\mathrm{n})$ & Mild OSA $(\mathrm{n})$ & & Primary snoring $(\mathrm{n})$ & Mild OSA $(\mathrm{n})$ \\
\hline Soft palate & 31 & 100 & 9 & 2 & 43 \\
Tongue base & 38 & 94 & 28 & 0 & 12 \\
Epiglottis & 11 & 4 & 0 & 1 \\
Tonsil & 5 & & &
\end{tabular}

OSA: obstructive sleep apnea
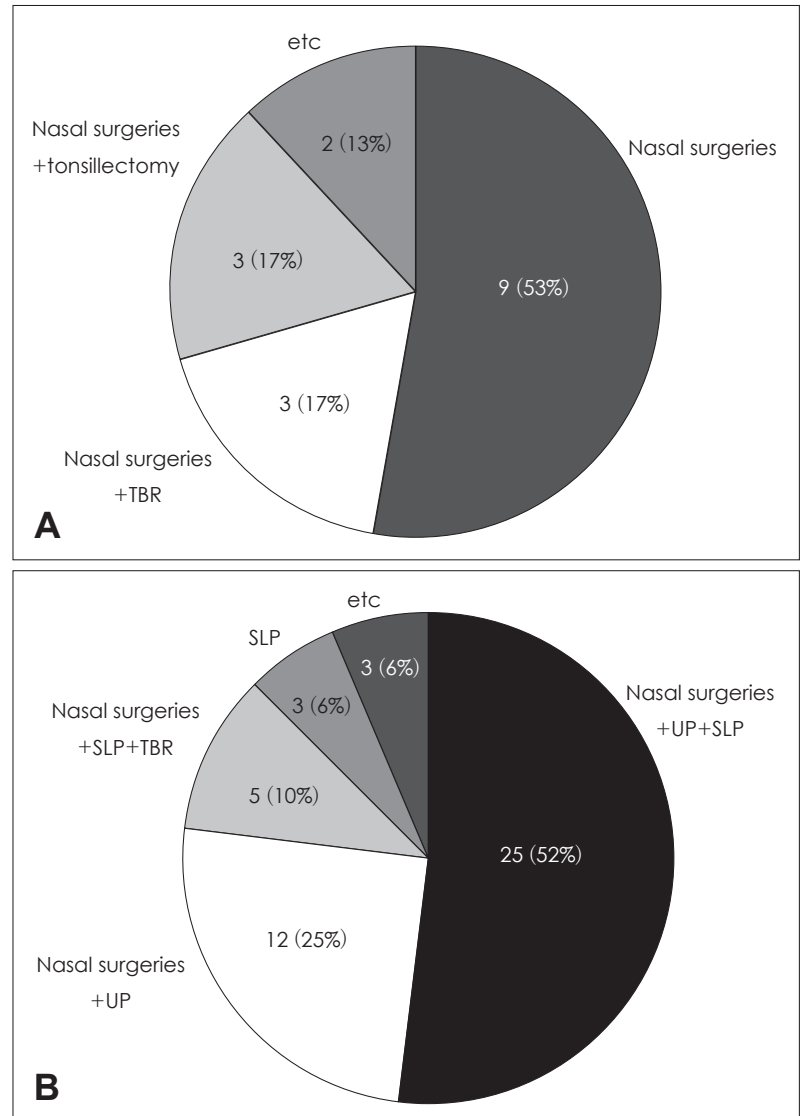

Fig. 2. Treatment methods of primary snoring and mild OSA. Treatment methods of primary snoring $(A)$. Treatment methods of mild OSA (B). OSA: obstructive sleep apnea, SLP: Suspension Lateral Pharyngoplasty, UP: uvulopalatoplasty, TBR: Tongue Base Reduction.

단순 코골이군은 치료 전후 코골이 $\mathrm{VAS}$ 와 $\mathrm{ESS}$, 그리고 PSQI를 비교하였다(Table 3). 코골이 VAS는 치료 전후로 유 의미하게 감소하였으나 $\mathrm{ESS}, \mathrm{PSQI}$ 는 감소하는 경향성은 확 인되나, 통계적으로 유의미하지는 않았다. 경증 폐쇄성수면 무호흡군은 치료 전후의 $\mathrm{AHI}$, 최저 산소포화도, 코골이 데시 벨, ESS, 그리고 PSQI를 비교하였다(Table 4). AHI와 코골이 데시벨, ESS, 그리고 PSQI 모두 치료 후 통계적으로 유의미하 게 감소하였고, 최저 산소포화도는 치료 후 통계적으로 유의 미하게 증가하였다.
Table 3. Treatment outcome of primary snoring

\begin{tabular}{lccc}
\hline & Prior to treatment & Following treatment & $p$ \\
\hline Snoring VAS & $6.9 \pm 2.3$ & $1.6 \pm 1.3$ & $0.005^{*}$ \\
ESS & $7.5 \pm 4.9$ & $3.0 \pm 0.0$ & 0.180 \\
PSQI & $9.5 \pm 3.5$ & $4.5 \pm 0.7$ & 0.180
\end{tabular}

$* p<0.05$ value was accepted as significant level. VAS: Visual Analog Scale, ESS: Epworth Sleepiness Scale, PSQI: Pittsburg Sleep Quality Index

Table 4. Treatment outcome of mild obstructive sleep apnea

\begin{tabular}{lrrr}
\hline & Prior to Treatment & Following treatment & \multicolumn{1}{c}{$\mathrm{p}$} \\
\hline AHI & $10.4 \pm 3.1$ & $6.1 \pm 4.5$ & $0.000^{*}$ \\
O lowest $(\%)$ & $84.6 \pm 7.2$ & $89.8 \pm 4.4$ & $0.005^{*}$ \\
Snoring $(\mathrm{dB})$ & $47.6 \pm 5.9$ & $44.2 \pm 4.2$ & $0.032^{*}$ \\
ESS & $9.0 \pm 4.7$ & $5.4 \pm 3.8$ & $0.001^{*}$ \\
PSQI & $8.1 \pm 3.5$ & $5.8 \pm 1.8$ & $0.009^{*}$ \\
\hline
\end{tabular}

$* p<0.05$ value was accepted as significant level. AHI: ApneaHypopnea Index, ESS: Epworth Sleepiness Scale, PSQI: Pittsburg Sleep Quality Index

양압기 또는 하악전방위치장치를 처방받은 환자 48 명 중 11 명(22.9\%)은 순응도가 좋지 않아 계속 사용하기를 포기하 였다. 그리고 하악전방위치장치와 수술을 받은 환자 1명은 증 상이 좋아져 하악전방위치장치를 사용하지 않게 되었다. 수술 없이 하악전방위치장치를 단독으로 처방받은 환자의 치료 전후 수면 척도를 비교하였을 때 $\mathrm{AHI}$ 와 ESS는 통계적으로 유의미하게 감소하였으나 $(p=0.005,0.042), \mathrm{PSQI}$ 는 통계적 의미를 확인할 수 없었다 $(p=0.136)$.

\section{고 찰}

단순 코골이군의 경우 경증 폐쇄성수면무호흡에 비해 적 극적인 치료를 받기로 결정한 환자가 적었다. 이는 객관적인 $\mathrm{AHI}$, 최저 산소포화도의 차이뿐만 아니라 주관적인 증상 역 시 단순 코골이군이 경증 폐쇄성수면무호흡군에 비해 적기 때문으로 생각된다. 그러나 본 연구에서 시행한 ESS, PSQI는 두 군 간에 유의미한 차이를 보이지는 않았고, 경향성만 확인 할 수 있었다. 이는 대상군의 수가 충분하지 않은 것이 원인이 될 수 있겠다. 
수술적 치료는 비중격 교정술 및 하비갑개 성형술이 큰 부분 을 차지한다. 이는 환자들의 수술적 치료를 결정하는 주요 원 인이 코골이 증상뿐만 아니라 코막힘 등의 비과적 증상 때문 일 가능성이 있다. 특히 단순 코골이군의 경우에는 53\%에서 비중격 교정술 또는 하비갑개 성형술만 시행하였기에 더욱 이러한 가정을 뒷받침해준다.

수면유도내시경검사의 결과에서 측와위에서 폐쇄 부위가 급격히 줄어드는 것을 볼 수 있다. 이는 중등도 이상의 폐쇄 성수면무호흡에 비해 단순 코골이와 경증 폐쇄성수면무호흡 에서 수면 자세 교정이 중요함을 보여주고 있다. Benoist 등하 의 최근 연구에서는 경증 폐쇄성수면무호흡 환자에서 수면 자세 교정 치료가 하악전방위치장치 만큼이나 효과적인 치료 임을 보고한 바 있다.

그리고 단순 코골이 및 경증 폐쇄성수면무호흡군의 환자 들은 대부분 연구개와 설기저부의 폐쇄를 보였다. 그러므로 해당 부위에 대한 치료가 객관적 그리고 주관적 수면 척도를 개선시키는데 중요함을 알 수 있었다. 폐쇄 부위의 결과를 봤 을 때 하악전방위치장치가 효과적인 치료로 생각할 수 있다. 본 연구에서도 하악전방위치장치를 통해 AHI 및 ESS의 호 전을 확인할 수 있었다. 다만 PSQI의 호전은 확인할 수 없었 다. 최근 하악전방위치장치의 효과에 대해 다양한 보고가 있 었다. 한 경증 및 중등도 폐쇄성수면무호흡증 환자의 무작위 대조연구에서는 하악전방위치장치가 $\mathrm{AHI}$ 를 감소시키지만 가장 중요한 증상인 중증의 주간기면증은 감소시키지 못한 다고 보고하였다. ${ }^{10)}$ 그러나 또 다른 무작위대조연구에서는 하악전방위치장치로 $\mathrm{AHI}$ 와 주간기면증을 모두 호전시킨다 고 보고하였고, ${ }^{11}$ 경증 폐쇄성수면무호흡 환자를 대상으로 한 다른 연구에서는 하악전방위치장치가 인지기능 및 정신 운동기능의 향상을 가져온다고 보고하였다. ${ }^{12)}$ 본 연구 역시 객관적 그리고 주관적 수면 척도 모두에서 호전을 보여, 후자 의 논문들과 일치하는 결과를 볼 수 있었다.

치료를 받은 단순 코골이군에서 분석한 수면 척도는 모두 주관적인 수면 척도로, 모두 치료에 반응하여 감소하는 경향 성을 보였으나 코골이 VAS만 통계적으로 의미 있는 결과를 보였다. 해당 군은 치료 후 수면다원검사를 시행한 환자가 1명 밖에 없어 객관적인 수면 척도를 분석하지 못하였다. 코골이 $\mathrm{VAS}$ 는 감소하였지만 $\mathrm{ESS}$ 와 PSQI는 유의한 변화를 관찰할 수 없었다. 단순 코골이군에서 치료가 환자의 삶의 질에는 큰 영향을 주지 않아 단순 코골이에서는 동반된 심혈관 질환 또는 인지장애 등이 없다면 적극적인 치료보다는 경과 관찰을 하는 것이 더 적절할 것으로 생각된다.

경증 폐쇄성수면무호흡 환자군에서는 모든 수면 척도에서 유의한 호전을 관찰할 수 있었다. 물론 앞에서 언급한 것처럼
$\mathrm{AHI}$ 와 증상 정도의 부족한 상관관계를 본 연구에서도 관찰 할 수 있었으나 경증 페쇄성수면무호흡 환자에서 증상이 있다 면 적극적인 치료를 권유하는 것도 효과적인 결과를 볼 수 있을 것으로 생각된다.

단순 코골이와 경증 폐쇄성수면무호흡의 치료의 필요성에 대해서 다양한 연구결과가 보고되고 있는데, Quan 등흐는 경증 폐쇄성수면무호흡과 수면, 감정, 삶의 질과 관련이 없음 을 보고하였고, Heinzer 드ㅇㅣㅡㄴ $\mathrm{AHI} 20$ 이상의 폐쇄성수면 무호흡만 고혈압, 당뇨 그리고 우울증과 같은 동반 질환과 독 립적인 연관성이 있음을 보고하였다. 반면 Luz 등ㄴ)은 경증 폐쇄성수면무호흡군이 정상군에 비해 집중력 저하를 보임을 보고하였고, Lisi 등 ${ }^{15)}$ 은 경증 또는 중등도 폐쇄성수면무호흡 군에서 확장기 심실기능부전과의 관련성을 보고하기도 했다. 본 연구에서는 단순 코골이군의 치료 결과는 만족스럽지 않 아 단순 코골이군에서 적극적인 치료는 큰 의미가 없다는 결 론을 내렸다. 하지만 본 연구는 수면장애와 관련된 동반 질 환을 함께 분석하지 않는 한계가 있었다. 기존 보고된 논문 들을 바탕으로 동반 질환의 유무와 증상 정도를 모두 고려 하여 치료를 결정하는 것이 바람직하겠다. 또한 경증 폐쇄성 수면무호흡군에서는 치료 결과는 단순 코골이군에 비해서는 모든 수면 척도의 호전을 보이지만, 동반 질환의 유무와 증 상 정도에 따라 치료의 강도를 결정할 필요가 있겠다.

본 연구는 몇 가지 한계점이 있다. 첫 번째로 대상군이 부 족하다는 점이다. 치료의 방법에 따른 치료 결과의 비교 분 석이 불가능한 부분이 있었고, 통계적 분석의 신뢰도 역시 부족한 점이 있다. 두 번째로 후향적 의무 기록 검토를 통한 연구 설계로 수면 척도의 정보가 치료 후 누락된 경우가 많 았다. 그리고 단순 코골이군과 경증 폐쇄성수면무호흡군에서 치료를 결정한 적응증이 불분명하고 동반 질환에 대한 정보 가 부족하였다. 세 번째로 대상군의 치료 전후 체중과 $\mathrm{BMI}$ 를 함께 분석하지 못했다는 점이다. 단순 코골이와 경증 폐 쇄성수면무호흡의 경우 체중 조절만으로도 증상의 개선을 볼 수 있어 해당 변수를 고려했어야 하나 후향적 연구의 한 계로 이를 조절하지 못해 결과의 신뢰도에 한계점이 있었다. 향후 전향적 설계를 통해 단순 코골이 및 경증 폐쇄성수면무 호흡 환자의 보다 적절한 치료에 대한 연구가 필요하겠다.

결론적으로, 본 연구의 결과를 토대로 본 연구자들은 단 순 코골이와 경증의 폐쇄성수면무호흡증 환자의 증상 조절 을 위해 반드시 수술을 포함한 적극적 치료가 필요하지는 않 다고 판단을 내리게 되었다. 하지만 폐쇄성수면무호흡증, 심 장질환, 및 인지 장애 등의 동반 질환이 있거나 수면파트너의 수면의 질에 영향을 미친다고 생각되면서 환자 자신이 주관적 인 수면 관련 증상을 호소하는 경우, 자동양압기(autoPAP), 
구강 내 장치, 수술적 치료를 고려할 수 있고 수면다원검사 수

치 자체의 감소보다는 환자의 증상을 줄이는 것을 목표로 치

료를 진행하는 것이 환자에게 도움이 될 것으로 생각된다.

\section{REFERENCES}

1) Heinzer R, Vat $S$, Marques-Vidal P, Marti-Soler H, Andries D, Tobback $\mathrm{N}$, et al. Prevalence of sleep-disordered breathing in the general population: the HypnoLaus study. Lancet Respir Med 2015;3(4): 310-8.

2) American Academy of Sleep Medicine Task Force. Sleep-related breathing disorders in adults: recommendations for syndrome definition and measurement techniques in clinical research. Sleep 1999;22(5):667-89.

3) Heinzer R, Marti-Soler H, Haba-Rubio J. Prevalence of sleep apnoea syndrome in the middle to old age general population. Lancet Respir Med 2016;4(2):e5-6.

4) Arnardottir ES, Bjornsdottir E, Olafsdottir KA, Benediktsdottir B, Gislason T. Obstructive sleep apnoea in the general population: highly prevalent but minimal symptoms. Eur Respir J 2016;47(1): 194-202.

5) Deegan PC, McNicholas WT. Pathophysiology of obstructive sleep apnoea. Eur Respir J 1995;8(7):1161-78.

6) Oh JE. Factors associated with habitual snoring. Korean J Health Promot 2011;11(1):18-24.

7) Banno K, Kryger MH. Sleep apnea: clinical investigations in humans. Sleep Med 2007;8(4):400-26
8) Kezirian EJ, Hohenhorst W, de Vries N. Drug-induced sleep endoscopy: the VOTE classification. Eur Arch Otorhinolaryngol 2011;268(8): 1233-6.

9) Benoist L, de Ruiter M, de Lange J, de Vries N. A randomized, controlled trial of positional therapy versus oral appliance therapy for positiondependent sleep apnea. Sleep Med 2017;34:109-17.

10) Marklund M, Carlberg B, Forsgren L, Olsson T, Stenlund H, Franklin KA. Oral appliance therapy in patients with daytime sleepiness and snoring or mild to moderate sleep apnea: a randomized clinical trial. JAMA Intern Med 2015;175(8):1278-85.

11) Quinnell TG, Bennett M, Jordan J, Clutterbuck-James AL, Davies MG, Smith IE, et al. A crossover randomised controlled trial of oral mandibular advancement devices for obstructive sleep apnoeahypopnoea (TOMADO). Thorax 2014;69(10):938-45.

12) Galic T, Bozic J, Pecotic R, Ivkovic N, Valic M, Dogas Z. Improvement of cognitive and psychomotor performance in patients with mild to moderate obstructive sleep apnea treated with mandibular advancement device: a prospective 1-year study. J Clin Sleep Med 2016;12(2):17786.

13) Quan SF, Budhiraja R, Batool-Anwar S, Gottlieb DJ, Eichling P, Patel $\mathrm{S}$, et al. Lack of impact of mild obstructive sleep apnea on sleepiness, mood and quality of life. Southwest J Pulm Crit Care 2014;9(1):44-56.

14) Luz GP, Guimarães TM, Weaver TE, Nery LE, E Silva LO, Badke $\mathrm{L}$, et al. Impaired sustained attention and lapses are present in patients with mild obstructive sleep apnea. Sleep Breath 2016;20(2):681-7.

15) Lisi E, Faini A, Bilo G, Lonati LM, Revera M, Salerno S, et al. Diastolic dysfunction in controlled hypertensive patients with mild-moderate obstructive sleep apnea. Int J Cardiol 2015;187:686-92 . 